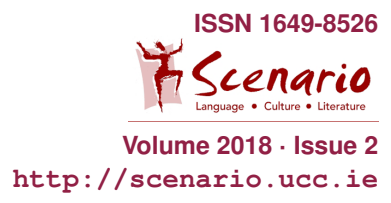

Tagungsbericht

\title{
6. SCENARIO Forum Symposium Report
}

\section{Eva Göksel \& Stefanie Giebert}

The symposium entitled 'Are Universities on the way towards a performative teaching, learning and research culture?' centred on the following questions: What exactly do we understand by a performative teaching and learning culture? Wherein exactly lies the benefit of applying performative approaches? How can we make university administrators and lecturers more aware of the immense innovative potential of going performative in higher level education ${ }^{1}$

*This dialogue represents a subjective impression of the SCENARIO Forum Symposium as expressed by two fictional characters. It is best enjoyed when read aloud and taken with a grain of salt.

Emily is typing.

E: (reading aloud) Okay. On September 21 and 22nd the 6th SCENARIO Forum Symposium took place in Hanover. It was organised by the Fachsprachenzentrum of Hannover University and the Staatstheater Hannover in conjunction with SCENARIO.

(Sabine enters, listening to Emily. She is obviously not very pleased by what she hears.)

$\mathrm{E}$ : The title of the conference was...

S: What are you doing?! I thought you were writing a report about a conference on performative teaching and learning.

E: Yes, that is in fact what I am doing.

S: You need to liven it up a bit!

$\mathrm{E}$ : What do you mean?

S: You should make it a performance!

$\mathrm{E}$ : As in...?

S: Okay, I'll dictate, you write.

E: Fine.

S: Act I - Scene I. Hanover. - A paved courtyard in front of an historical building in the old town. DANIEL - in capitals, please - in front of the building. ENTER SABINE. That should be in italics, it's a stage direction.

E: Okay...

S: Okay, let's continue. DANIEL: Hey! Over here! It's Sabine, isn't it? SABINE: Hi! Nice to see you again!

E: Oh, no, we're not falling into the old 'let's write like Shakespeare' cliché. By the way, if we were, he should have said: "Who's there?" and you should have replied: "Nay, answer me!"

1 https://www.ucc.ie/en/scenario/news/ 
S: Okay, fine. How about: It was a grey and drizzly day...

E: (groans) Not that overused line again. I thought you wanted to be creative.

S: I just wanted to let the readers share what we saw, and heard, and tasted... You tell me what we should write then.

E: How about starting at the beginning.

$\mathrm{S}$ : But what was the beginning? When does the theatre start?

E: Wait! You're getting ahead of yourself. Why don't we start with the chairs?

S: Ah yes, we began by sitting in the audience and...

E: Actually, I meant Fionn Woodhouse's comment about creating a performative university - one without chairs! Or, at least a university with mobile chairs.

S: Ah. I see. Yes, I'd certainly appreciate that in my classroom. But how could such an idea be implemented? Who would pay for it?

E: We'll leave that to the experts. We should start by reporting on the series of short talks that took place on the first afternoon.

S: Ah yes, the Sonnenstrahlen. They were quite enlightening.

E: Pun intended, I hope.

S: Ha ha. So, when does the theatre begin?

E: Yes, let's talk about that now. That was what Niklas Hald was pondering during his talk. In his $\mathrm{PhD}$, Niklas asks what it means to be an actor. He began his talk with a personal anecdote about his days touring a one-man show for children. After a rather hectic start at the venue, he began the show. A short time later, he heard a child's voice in the audience asking: "Mommy, when does the theatre start?"

S: Yes, that certainly made him think. And it made me think about my performance as a teacher. I mean, when does my "show" start? Is it when I enter the classroom? Is it while I am setting up? For me, it starts when I greet my students. Before that, I guess I pretend that I'm behind an invisible curtain. I feel that gives all of us a chance to settle in before the lesson begins.

E: For Niklas, however, the show starts the night before, while he gets into character.

S: My show also sometimes starts the night before. I sometimes wake up in a panic in the middle of the night wondering if I've really prepared all my lessons or printed all my materials.

E: Don't be so melodramatic.

S: But it's true. The question of when the show begins is highly relevant for teachers. And when does it end? I mean, when do I stop being a teacher?

E: That's easy. Never.

S: I'm quite serious. After all, the actor doesn't have to be Hamlet 24 hours a day. Even as a teacher I need some time off, I do have other roles in my life.

E: Well, I think you'll be interested to know that many children are quite surprised to find out that teachers exist outside of school.

S: Really?

E: Yes indeed. A wonderful fictional example can be found in Roald Dahl's Matilda. Upon getting to know her teacher better, young Matilda realises that 
she "had never once stopped to think about where Miss Honey might be living. She had always regarded her purely as a teacher, a person who turned up out of nowhere and taught at school and then went away again." ${ }^{2}$

S: Okay, now you're getting off track. Let's move on to Ulrike Jäger's talk. What struck me was her revelation about the power of teacher performance in a university setting. She realised that if she delivered a really good computer science lecture, her students tended to lean back to enjoy the show. Optimising her performance seemed to lead to suboptimal student engagement. Once she realised this, she began to raise the stakes for her learners by engaging them in project based learning.

E: Well, that's pretty risky, after all if we encourage the students to start making their own decisions, who knows what the outcome and consequences will be.

S: Indeed. Ulrike also pointed that out. I actually feel that it's a lot like improv theatre, because you never quite know what will happen next. However, just as improv has rules, so does project-based learning. Ulrike used the metaphor of guard rails to describe her model of structure and feedback.

E: I suppose it's like Vygotsky's zone of proximal development; if the challenge of the work is pitched at the right level, just a bit beyond the learners' current ability, then they will be interested in growing their knowledge.

S: (sings) Growing. Yeah. Knowing. Yeah.

$\mathrm{E}$ : What are you doing now?

S: I'm just warming up; the next talk was all about slam poetry! Don't you remember? Nils Bernstein shared his experience of teaching German as a foreign language to university students. He asked them to translate an academic article into rhymes. I'd love to read more articles like that.

E: I'll bet you would. Look at what you are doing to this conference report.

S: Well, I think it will be more memorable than your dry and boring attempt would have been. However, what we are missing is the performative element of sound. This report would be a much better performance if we were to read it aloud. Then we could work on our articulation and the projection of our voices. The experience would also encourage us to think about our breathing and posture. Nils felt strongly that all of these skills could be polished in his slam poetry class in addition to vocabulary and grammar.

E: I see. Well then, which talk came next? Ah yes, Eva Göksel shared her experience of helping to build a Drama in Education movement at her university of teacher education in Switzerland. Drama is being pioneered in various courses in a range of departments including foreign language teaching. Drama in Education is not part of teacher training in Switzerland and-

S: Ah, ravioli!

E: Are you getting hungry?

S: A bit. But actually I was referring to Eva's example. (starts rapping)

She talked of a student teacher / trained in $\mathrm{DiE} /$ who taught a grade three class / the wonderful storee / of Armand, doing boring chores / in the ravioli

\footnotetext{
2 Dahl 1988: 176.
} 
factory!

E. (groans) Stop it, please. The children used mime and not rap in that example.

S: I know. And I also know that in the next talk Kurt Schneider talked about agile software development. He shared his experience teaching a university computer science course in which students develop products for real customers.

(E. is looking at her mobile phone.)

S: Hello, are you listening to me? What are you looking at?

E: Hmm? Oh, I'm just checking out the app Kurt's students recently developed: "Theater-O-Mat". It helps you pick out the right play to watch. For example if you are in the mood for "bloody and brutal, opulent, with live music" then you should go watch Macbeth at the Staatstheater Hannover.

S: Now look at who is getting off track.

E: All right, all right. (puts phone away) In the next talk, Edith Karimi shared her thoughts on mimesis.

S: Yeah, she had some interesting ideas about it, arguing that imitation has its place next to creativity, as it is an important part of the aesthetic process. It's great to see a concept like this revisited and refreshed.

E: (yawning and stretching)

S: Okay, what are you up to now? Do you need a break?

E: That's exactly what Fionn Woodhouse and Róisín O'Gorman offered us in their contribution "Articulating the Bones".

S: And what did your bones tell you?

E: They told me that I shouldn't forget their existence just because of all the exciting stuff my brain was given to process since the start of the conference.

S: Mine were of the same opinion. Finally, something we agree on. After all, we're not brains in a tank.

E: You and your metaphors... After that, the final talk of the evening was held by Claudia Müller. One of the ideas she shared has really stuck with me: She presented us with a wonderful image of graffiti on an old stone wall. She called the graffiti a "Befundstörung".

S: Why? What does it mean?

E: Well, as I understand it, someone had disturbed an object of historical interest. The wall, apparently, has a long history, as it had been created as part of an ancient defence system and it even includes pieces of Roman tombstones. The graffiti was encroaching on the wall's story.

$S$ : Or adding another layer to it.

E: Precisely. Now you're getting it.

S: Okay, I'm getting really hungry now, let's take a break before we discuss the second day of the conference.

E: Alright, but we should just mention that we went to see a play in German at the Staatstheater on the first evening: "Acts of Goodness" gave us all food for thought.

S: Indeed, I felt that the choice of play was very fitting, in more ways than one. After all, don't we, as Drama in Education practitioners, also have the best 
of intentions, like the characters in the play? But perhaps what we do is not always helpful for or appreciated by our learners?

$\mathrm{E}: \mathrm{Hmm}$, you're getting self-critical. Interesting. Let's discuss that over lunch.

(Half an hour later)

$\mathrm{E}$ : (still chewing) I would never have thought it, but doing this report is actually fun. I feel like a lighting technician - highlighting different moments of the event and sharing our thoughts about them. So, here we go, day two of the conference.

S: (whistles and claps)

$\mathrm{E}$ : Was the break too short for you?

S: Oh, I was just spelling the word "performative".

E: Ah, you mean like we did with Manfred Schewe at the beginning of his talk "Der Traum vom leeren Raum - Perspektiven einer Performativen Lehr-, Lern- und Forschungskultur". Yes that was a very eventful talk, wasn't it?

S: It certainly was, from Goethe's Faust to Peter Brook, to the anatomical theatre, we were invited to think about the spaces in which we perform.

E: Schiller and Shakespeare also put in an appearance...

S: And don't forget the dragon!

E: Don't confuse the readers, there was no mention of Tolkien or Game of Thrones.

S: I'm talking about Manfred's experiment with the story of the green dragon, which he used to elicit students' responses to something unknown and unexpected entering their world.

E: Yes, he did the experiment with us too: We were asked to write about our reaction if a green dragon were unexpectedly to knock at our door. Both the students' and our own reactions were quite surprising for many of us.

S: What surprised me most, however, was a member of the audience getting up in the middle of Manfred's talk to move a vase of flowers around the room.

$\mathrm{E}$ : Yes, that was an unexpected performative element. Manfred had randomly assigned someone a joker card, so even he did not know what exactly would happen, or when. In fact, I felt a bit like that regarding the second talk.

S: What do you mean?

E: I was looking forward to Michaela Sambanis and Maik Walter's lecture performance, mainly because I didn't know what to expect.

S: I really enjoyed how group work was integrated into the talk in order to reinforce the concepts presented.

E: Yes, the talk's title was very fitting: "Und Action! Vom Hirn ins Herz bis in die Füße". It focused on how the brain learns better with movement. The group work, led by Maik, invited us to use movement to revisit the talk's key concepts.

S: Yes, I still remember many of the tableaux presented, there was one representing Praxisschock, one for the language lab and-

E: (sings) Es geht um das Gedächtnis.

S: Ah yes, the second group work task. Lernen. Learning. Apprender. ...

E: We recreated different types of memory. Your group portrayed semantic memory and mine portrayed associative memory. 
There was also procedural, episodic and declarative memory. I really enjoyed this hands-on way of revising the content of the talk.

S: Me too. I also liked the newspaper headlines we created in the third activity, summing up the essence of the talk. And I quite enjoyed the lunch afterwards.

E: Thinking with your stomach again. So, what did we do in the afternoon?

S: Well, there was quite a selection of workshops to choose from. I attended Róisín O’Gorman's workshop "Embodied Movement Awareness: Articulating Structure and Flow Across and Through Disciplines". We spent time with our bodies, experimenting with different types of movement to music.

E: I attended Fionn Woodhouse's workshop "Sticky Impact - Building Teaching and Learning on Performative Practice". As a group we developed variations of drama activities for the language learning classroom. Who knew that one activity could be used in so many different ways.

S: There were many other workshops to choose from: About staging learning processes, performing poetry, teaching technical language with drama, reflecting practical knowledge...

E: Yes, it's too bad we couldn't split ourselves into three just for the afternoon to attend them all.

S: Indeed. The limits of the body again... Well, shall we call it a day? My stomach is grumbling.

E: Again? Okay, we just need to report on the final plenary. We were given the opportunity to contribute our thoughts to a position paper on promoting a performative teaching, learning, and research culture in higher education.

S: I'm curious to see how this develops further.

$\mathrm{E}$ : Me too. I know that the paper is available in German and English on the SCENARIO website: https://www.ucc.ie/en/scenario/news/

S: Great, so our hard work paid off. After that we were able to take home some leftover sandwiches.

E: Well, I hope you were able to take home more than that.

S: Ha ha. Of course, I attended the conference with brain, stomach, heart and feet.

E: On that note, let's call it a wrap. It was a successful event and I look forward to the next one.

S: By the way, the wraps at the lunch buffet were also delicious.

E: Enough already. Let's go have some dinner.

Both exit stage left.

\section{Bibliography}

Dahl, Roald (1988): Matilda. New York: Puffin 